\title{
Ergonomia e Design de Emoção no Desenvolvimento do Vestuário
}

Ergonomics and Emotion Design in the Garment Development

\section{Naiane Cristina Salvi}

Mestranda em Gestão Estratégica do Design pela UFSC nai.salvi@gmail.com

\section{Eugenio Andrés Díaz Merino}

Doutorado em Engenharia de Produção pela Universidade Federal de Santa Catarina eugenio.merino@ufsc.br

\section{Francisco Antonio Pereira Fialho}

Doutorado em Engenharia de Produção, Engenharia do Conhecimento, pela Universidade Federal de Santa Catarina 


\title{
Ergonomia e Design de Emoção no Desenvolvimento do Vestuário
}

\author{
Naiane Cristina Salvi,-Eugenio Andrés Díaz Merino e Francisco Antonio Pereira \\ Fialho
}

\section{Resumo}

A tendência que aponta um crescimento do consumo de bens de vestuário partindo do conforto gerado em sua utilização motiva este estudo, que propõe compreender os fatores que auxiliam na construção de peças tradicionais do vestuário estreitando as relações com a ergonomia e propiciando positivas experiências de uso. Tendo em vista que, segundo a ergonomia, a satisfação plena dos desejos do usuário perante um produto se dá por meio da sua adequação técnica, ergonômica e estética, o que oportuniza uma estruturação de novas soluções para o desenvolvimento de peças de roupa. Este estudo apresenta conceitos a cerca do aprimoramento de formas, no intuito de incentivar a busca pela satisfação de usuários perante os produtos de moda, tendo em vista a sua importância na diferenciação entre objetos similares já presentes no mercado, bem como a afirmação de marcas com valores voltados à preocupação com o bem-estar de seus consumidores.

Palavras- chave: Ergonomia, Vestuário, Design.

\begin{abstract}
The trend indicates that an increase in the consumption of apparel goods leaving the generated comfort motivates its use in this study, which proposes understand to factors that assits the construction of traditional clothes strengthening links with ergonomics and providing positive use experience. By understanding that, about ergonomics, the full satisfaction of the costumers before a product occurs between it technical adequacy, ergonomic and aesthetic, that provides opportunities for development of new solutions in the construction of these garments. This search involves the application of concepts for further development of the form in order to encourage the pursuit of satisfaction of users towards fashion products, in view of its importance in differentiation from similar already on the market as well as the statement brands with values geared towards concern for the well being of their customers.
\end{abstract}

Keywords:Ergonomics, Garment, Design 


\section{Introdução}

Produtos cuja utilização gera bem-estar e adaptação a particularidades provocam na indústria de moda uma preocupação bastante motivada para a aproximação dos produtos aos seus usuários. O desenvolvimento de novos tecidos e materiais, o teste de caimento e comportamento do produto durante o uso, bem como, a forma apresentada pelo produto compõe sua construção técnica, enquanto contribuem também como recurso ergonômico. Neste processo, é essencial também, que seja considerado o contexto estético, tendo em vista que para um produto de moda este é fator primordial na exploração do consumo.

Neste cenário, objetiva-se identificar conceitos que baseiam o desenvolvimento de novas possibilidades de construção de produtos convencionais, permitindo a elaboração de um novo produto mais apto às atribuições ergonômicas, enaltecendo a importância da adequação de materiais e suas inovações que permitam a ampliação do conforto e estética do produto, para a percepção de características perfeitamente adaptadas a eles.

O desenvolvimento de produtos de moda associados à ergonomia é um desafio para a indústria de moda, embora representem uma verdadeira carência no mercado já que suas extensões são pouco exploradas pela indústria. Porém, para um cenário globalizado, com uma grande abertura ao acesso a informação, como também pela grande concorrência que se apresenta a conquista ao consumidor deve ser imediata, além da necessidade de respeitá-los promovendo discursos éticos e transparentes (SALVI, SCHULTE, 2014). Para que esta conquista e transparência sejam eficazes é necessário o uso de ferramentas capazes de gerar resultados diferenciadores e de captar os desejos e intensões do consumidor que permanecem, muitas vezes, ocultos.

Conforme Iida (2005, p. 313) "Do ponto de vista ergonômico, os produtos são considerados como meios para que o homem possa executar determinadas funções". Para isso se faz uso da ergonomia para a criação de produtos capazes de unir a forma do corpo humano com materiais ideais para a construção de peças de vestuário. Esses produtos são compostos por apelo estético e econômico, o que caracteriza um produto diretamente ligado à qualidade, e que pode apresentar um diferencial perante produtos convencionais, gerando assim, um consumo emocional.

Observa-se que esta necessidade de desenvolver produtos de moda ergonômicos, parte, principalmente, do crescimento das exigências por parte dos consumidores, que 
envolvem em sua expectativa a satisfação plena na utilização de um bem ou serviço. Reconhece-se que sua aplicação sofre resistência por exigir profissionais capacitados e tempo para desenvolvimento de projetos adequados ao biótipo de seus consumidores e ao tipo de produtos oferecidos pela empresa. As prerrogativas negativas são reforçadas ainda pelo fator econômico, limitador da maioria das ações ergonômicas relacionadas a produtos. Mas em contrapartida, observa-se que a indústria de moda tem dado atenção a necessidade de integração da ergonomia no processo de desenvolvimento de vestuário na finalidade de promover a satisfação do usuário e da qualidade experiencial do produto (CAPELASSI; VALARELLI, 2010).

Assim, este estudo propõe a apresentação de conceitos relacionados à ergonomia para o desenvolvimento de produtos de moda capazes de gerar soluções eficazes e aptas a serem empregadas na indústria sem significativos impedimentos. Compreende-se que, neste mercado, os poucos produtos já oferecidos que oportunizam o conforto nem sempre são trabalhados esteticamente, e são em geral direcionados a faixa etária de terceira idade, enquanto que produtos que primam pela aparência carecem, muitas vezes, de uma adaptação técnica e ergonômica.

Em termos metodológicos, partir-se-á de uma pesquisa bibliográfica qualitativa, através da análise de autores na busca de conceitos e coleta de informações a respeito de moda e ergonomia para fundamentação deste estudo, no qual serão apresentados os conceitos em uma relação com as atribuições destacadas ao desenvolvimento de produtos de moda.

\section{A ergonomia no desenvolvimento de produtos de vestuário}

Dentre as definições de ergonomia existentes, adotamos aquela que julgamos ter uma melhor relação com as questões de produtos propriamente ditos, e que melhor orientam este trabalho. Sendo assim, para a IEA (International Ergonomic Association) "Ergonomia (ou Fatores Humanos) é a disciplina científica, que estuda as interações entre os seres humanos e outros elementos do sistema, e a profissão que aplica teorias, princípios, dados e métodos, a projetos que visem otimizar o bem-estar humano e o desempenho global de sistemas" (definição internacional de ergonomia - IEA, International Ergonomics Assossiation -, 2000). 
Iida (2005) apresenta três domínios da ergonomia, sendo elas Física, Cognitiva e Organizacional. No que tange o desenvolvimento de produtos, bem como seu consumo, pode-se dizer que as três abrangências são aplicáveis a este estudo.

A ergonomia física complementa o estudo das formas, das dimensões fisiológicas, bem como a movimentação do usuário na utilização das roupas. Além disso, se concretiza por meio dos tecidos aplicados, já que estes são diretamente ligados ao resultado desejado para o produto.

Na continuidade, a ergonomia cognitiva se relaciona à percepção do produto pelo usuário, e assim, é aquela que se apresenta quando o usuário experimenta a sensação de conforto, de satisfação e de bem-estar. Pode-se dizer que é o resultado almejado pelo produto.

Por fim, a ergonomia organizacional, que não diretamente se relaciona ao produto, sempre deve primar o bem-estar de seus clientes, bem como de seus funcionários, proporcionando assim, a geração de valores perceptíveis por todos os envolvidos na origem e desenvolvimento de seus produtos.

Em consequência desta visão, se aplicam os diferentes domínios da ergonomia como a disciplina que orienta a construção de uma peça de vestuário capaz de satisfazer as necessidades humanas, complementando todos os fatores envolvidos, objetivando acima de tudo o bem-estar de todos os participantes do processo.

A partir disto, pode-se afirmar que a satisfação dos participantes, e acima de tudo, do usuário final, estando relacionada às suas emoções caracteriza a aplicação primordial da ergonomia cognitiva, que "[...] ocupa-se dos processos mentais, como a percepção, memória, raciocínio e resposta motora, relacionados com as interações entre as pessoas e outros elementos de um sistema" (IIDA, 2005, p. 330).

A ergonomia cognitiva voltada a produtos está diretamente relacionada ao design emocional, criando uma fusão por meio do relacionamento de seus objetivos. $\mathrm{O}$ design emocional é a união da área do design com a emoção, e concretiza-se na intenção de oferecer ao usuário uma experiência prazerosa, que lhe provoque anseio, contentamento e consequentemente, se torne uma referência positiva na vida do consumidor, fazendo com que ele volte a consumir os produtos e o indique a demais pessoas de seu círculo de relacionamento (NORMAN, 2008).

Ainda que aqui explorado também com desígnio comercial e econômico, o design emocional objetiva proporcionar ao consumidor uma interação significativa com 
aquilo que ele se relaciona, partindo não apenas do consumo por si só, mas que de alguma maneira lhe acrescente em termos culturais, emocionais e em experiências.

No que envolve a criação e o desenvolvimento de produtos, fatores de qualidade como funcionalidade, conforto e estética precisam ser percebidas pelo usuário para este possa aplicá-la na sua percepção do produto e assim, valorizar as singularidades presentes na peça (CAPELASSI; VALARELLI, 2010). Carvalho (2013) complementa neste sentido, "a sensação física que um produto causa é importante, pois somos criaturas biológicas, [...]. Entretanto, há uma grande parte no cérebro que é ocupada pelos sistemas sensoriais capazes de interagir com o ambiente." (CARVALHO, 2013, p. 46).

Neste sentido, compreende-se que a construção de produtos de vestuários aptos às necessidades físicas do corpo humano tendo como principal objetivo o conforto torna-se uma importante característica na diferenciação dos produtos já existentes no mercado. A reconstrução das roupas tradicionais sob os aspectos que priorizam o bemestar do usuário e não apenas a adequação ao formato do corpo humano geram uma experiência positiva, e acrescentam ao produto um diferencial até então pouco explorado.

Para Iida (2005), os produtos devem satisfazer três variáveis fundamentais, sendo elas, qualidade técnica, ergonômica e estética, ou seja, deve ser eficiente em termos técnicos, adaptado ao usuário em questões ergonômicas, e esteticamente agradável, sob as perspectivas do próprio usuário.

Estes fatores de qualidade presentes, simultaneamente, em um produto caracterizam um produto ergonômico, e podem ser percebidos pelo usuário.

Rosa (2011) aponta que a ergonomia é aplicada ao vestuário de maneira intuitiva. Ou seja, as empresas não dispendem os devidos estudos no desenvolvimento de seus produtos para atingir as necessidades e as oportunidades disponíveis pela exploração ergonômica aplicada ao vestuário. Tais explorações poderiam abranger o desenvolvimento de produtos com itens de segurança e conforto, baseando-se na antropometria, fisiologia, psicologia e ainda sociologia ao se inserir em um meio social.

Segundo Silveira (2011) para que um produto possa ser considerado ergonômico, ele deve obedecer a sete critérios, sendo eles, função de uso, facilidade de uso, segurança, conforto, durabilidade, estética e ainda possuir um preço acessível. 
A função uso está baseada na utilização de três limitadores, a adequação de materiais, a adequação antropométrica e a adequação funcional (SILVEIRA, 2011). A utilização adequada destas variáveis permite a geração de um produto cuja construção física complementa as necessidades do ser humano, e o torna um produto adequado ao seu uso, ou seja, não apresenta complicações ou desconforto ao ser utilizado.

Além disso, os produtos devem ser fáceis de serem empregados e usados, e precisam zelar pela segurança do usuário (SILVEIRA, 2011), logo, não apresentando riscos de acidentes ou imobilidade física que possam gerar qualquer tipo de dano à saúde do consumidor. Os produtos devem apresentar também conforto e durabilidade, ou seja, devem ser agradáveis de serem utilizados (SILVEIRA, 2011). Assim sendo, os produtos devem garantir o bem-estar ao usuário, tanto física quanto cognitivamente e ainda apresentar o máximo de durabilidade de suas características iniciais, ou seja, possuir o menor nível possível de depreciação.

A função estética, para a autora, deve ser contemplada para que o produto seja atrativo ao consumidor. Assim, não basta que ele seja confortável e funcional, pois o consumo partirá da identificação do usuário no momento anterior ao contato físico, e assim, o produto deve-se destacar visualmente dos demais, e posteriormente ser percebido como um produto confortável e adequado às funções e necessidades do usuário (SILVEIRA, 2011). Além disso, a função estética envolve os estímulos visuais provocados pelo produto.

As aplicações dos conceitos ergonômicos durante o desenvolvimento de peças de vestuário se dá, principalmente, pelo processo de modelagem e definição dos materiais empregados. A correta definição dos cortes e construção física dos produtos, bem como a aplicação de materiais adequados para cada finalidade é imprescindível para o alcance da eficiência de um produto com apelo ergonômico.

Por fim, o produto deve apresentar um preço acessível, para que esteja ao alcance do consumo do público para o qual foi projetado. É fundamental que os produtos possuam preço adequado ao mercado no qual estão inseridos, para que não se desvalorizem em relação aos demais, assim como não devem possuir preços exorbitantes que assustem o consumidor.

Desta maneira, pode-se concluir que os produtos ergonomicamente adequados, são projetados a partir de uma soma de fatores, cujos direcionamentos contemplam os 
diversos elementos de um produto, e são utilizados a fim de proporcionar ao usuário máxima satisfação na sua utilização.

\section{Design de Experiência e o Consumo Emocional}

O design pode ser entendido como uma atividade aplicada na geração de projetos, como método ou ferramenta que engloba o desenvolvimento planejado de determinado objeto.

Já a emoção apresenta-se na função de "conectar a natureza animal dos indivíduos no mundo onde estão imersos, respondendo imediatamente à verdade das coisas, sendo considerada a forma mais alerta de atenção" (CARVALHO, 2013. p. 4).

O design de emoção, por sua vez, é a ferramenta que proporciona a compreensão das emoções humanas durante a fase de desenvolvimento de projetos, objetivando focar no resultado das experiências de uso, tendo em seu escopo a construção de um produto ergonômico.

Carvalho (2013) descreve a emoção como a combinação de um processo de avaliação mental, bem como as respostas resultantes deste processo. Assim, o estudo das emoções quando dirigidas ao resultado de experiências na utilização de produtos, direciona a sua criação levando em consideração fatores cognitivos, cuja aplicação agrega valores ergonômicos na satisfação do usuário.

Ainda sobre emoção, a autora esclarece que esta "pode ser considerada um reflexo do comportamento do corpo, capaz de expressar sentimentos que são enviados conscientemente pela mente, o que se torna possível através do contato físico ou apenas visual que o indivíduo pode ter com os produtos" (CARVALHO, 2013, p. 11), e que "as emoções são instrumentais aos indivíduos, e passam a servir como ferramenta de adaptação, fazendo com que as emoções aproximem as pessoas às coisas e às ideias, entretanto, é também capaz de afastá-las" (CARVALHO, 2013, p. 12). Destas afirmações pode-se destacar que é por meio das emoções geradas pelos produtos que o consumidor o perceberá, ou seja, um produto chamará a atenção de determinado indivíduo por meio da geração de emoção ao ter sido visto, tocado ou experimentado.

Quando o usuário se identifica com determinado produto, primeiramente por meio do seu apelo estético e em seguida intensificada pela experiência de uso, criam-se elos de afetividade. Estes elos são observados tanto em produtos, quanto em marcas ou serviços. É comum identificarmos relatos positivos quando o consumidor se surpreende 
com a experiência vivida no contato com determinados produtos, assim como é forte a negatividade das frustrações quando os mesmos se decepcionam com um atendimento ou com defeitos inesperados em bens adquiridos.

Neste caso, as emoções provocadas pelos produtos ou serviços geraram uma emoção, e esta emoção foi relacionada diretamente a um sentimento. Logo aquele produto passou a representar este sentimento para o usuário, seja ele bom ou ruim. Segundo Damásio (2004, p.12), “[...] os sentimentos são por sua vez um processo cognitivo ou mental que são resultantes da emoção que, diferente da emoção, são relativamente mais estáveis".

Os sentimentos são contínuos, mesmo provocados pelas emoções que são momentâneas. Eles são vividos no íntimo e podem ser disfarçados, ainda que muito fortes. "O ser humano é capaz de analisar, interpretar, organizar e refletir sobre os próprios sentimentos, ou seja, consegue construir sentimentos a partir disto" (CARVALHO, 2013, p. 13).

Estes conceitos orientam o desenvolvimento de novos produtos, cercados de um apelo emocional prosaico para a geração de experiências prazerosas que por sua vez, resultam em sentimentos positivos.

Assim, “[...] a união destas duas vertentes - Design e Emoção - ocasionou um crescimento de experiências prazerosas entre os indivíduos e os produtos que os cercam" (CARVALHO, 2013, p. 16). A autora reforça as relações entre as duas áreas afirmando que "[...] resultou num novo pensamento decorrido nos anos atuais, o que realiza a materialização das sensibilidades e valores humanos, influenciando assim na importante inclusão dos fatores emocionais do desenvolvimento do produto" (CARVALHO, 2013, p. 16).

Logo o papel do designer no desenvolvimento desses produtos, oferece uma gama de possibilidades na intenção de ofertar ao consumidor produtos adaptados àquilo que lhes é desejado e necessário. É função destes profissionais zelar pelas necessidades do consumidor, compreendendo que este, mesmo que inconscientemente, está esperando para ser surpreendido a todo o momento.

O designer deve então, identificar formas, métodos, materiais e a representação fiel dos signos com os quais o seu consumidor irá se identificar. É necessário conhecer este consumidor a fundo, saber de todas as suas particularidades, para que o produto 
possa transmitir ao seu portador uma comunicação compreensível e passível de ser captada.

A compreensão destes discursos que o produto deve carregar é o que gera a identificação do usuário e logo, cria uma experiência.

Reforçando a relação entre produto e usuário, Carvalho (2013) atesta sob o espectro da modernidade, “[...] onde a interação com o produto também participa na construção da individualidade complexa do cenário existente" (CARVALHO, 2013, p. 19). Segundo a autora é por meio desta interação dos significados, com a compreensão ideológica dos produtos que ocasiona experiências positivas e prazerosas com estes objetos, que tornarão o indivíduo diferente dos demais, ou seja, por meio da utilização destes produtos, o consumidor se sente único, reforçando sua personalidade e seus valores particulares perante a sociedade.

Em relação a isto, a psicologia prescreve que o ser humano é capaz de aumentar suas expectativas em relação a produtos quando suas primeiras expectativas são supridas. Ou seja, o cérebro aumenta o grau de expectativa em relação à interação com determinado objeto, quando a primeira experiência tiver sido acima daquilo que ele havia imaginado inicialmente (NORMAN, 2008).

Este contexto reforça a necessidade de um perfeito funcionamento e delimitação adequada dos produtos, para que sua usabilidade, conforto e funcionalidade estejam sempre à frente das expectativas do usuário. É importante ressaltar também, que a durabilidade torna-se um fator primordial no alcance desta finalidade, já que os produtos devem apresentar uma vida útil superior ao que o usuário espera, sem apresentar defeitos ou desgastes precoces.

Para isso, o designer lança uso das qualidades ergonômicas, capazes de interagir com as qualidades físicas e simbólicas que agregam valores invisíveis aos produtos, mas que podem ser captados e percebidos pelo usuário sem grandes dificuldades, motivando o consumo emocional.

A respeito do consumo, Carvalho (2013) aponta três etapas que envolvem a busca, a escolha ou a compra em si, e a pós compra. A primeira etapa é motivada por necessidades ou por identificação, muitas vezes determinada por ações de marketing e pressão social. A busca tende a suprir carências do usuário, carências estas que nem sempre são guiadas pela razão, ou seja, são involuntárias e quase imperceptíveis. Em segundo lugar, a compra é quando o consumidor toma sua decisão, é o momento no 
qual o produto deve prevalecer, logo, suas características físicas e emocionais devem estar muito próximas do consumidor. Por fim, o pós compra, é quando o usuário efetivamente interage com o produto e onde suas emoções são atestadas para a geração de sentimentos em relação ao produto (NORMAN, 2008).

As três etapas concluem o processo de compra de quaisquer bens ou serviços, e são intensificadas por marcas, apelos estéticos, emocionais, sociais ou ainda culturais, como afirma Carvalho (2013), "[...] a cultura pode ser considerada o principal fator que determina o comportamento e o que ocasiona os desejos de um consumidor" (CARVALHO, 2013, p. 26), pois ela, assim como a posição socioeconômica, funciona como espectro para a visibilidade de necessidades e carências, bem como alteram a compreensão dos produtos.

Assim, a moda funciona como "[...] um fenômeno sociológico, só acontece se existirem pessoas que creem, aceitem, e logo, consumam" (CARVALHO, 2013, p.35), todos os bens, por mais fundamentais que sejam só alcançam seu objetivo se forem aceitos pelos consumidores, se existirem usuários que se identifiquem com as propostas do produto e as consumam e sejam seus adeptos, coniventes com as ideologias transmitidas.

\section{Considerações Finais e Conclusão}

Um produto de moda desenvolvido sob os aspectos ergonômicos tem o intuito de priorizar as sensações e as emoções do usuário durante a utilização de produtos. É desenvolvido sob o viés do design emocional, cujos projetos se assemelham às finalidades ergonômicas, interligando-se por meio das características físicas dos produtos para a geração de experiências cognitivas positivas e prazerosas.

Todo e qualquer produto de design deve acima de tudo primar pelo bem-estar do seu usuário, e este é outro objetivo compartilhado com a ergonomia. Sendo assim, deve suprir suas necessidades e desejos e acima de tudo, ser percebido pelo consumidor.

O design emocional propõe que esta percepção seja motivadora de emoções benéficas, e assim, o produto além de ganhar o respeito do consumidor por meio de identificações, gere relações de afeto com o usuário.

Quando tratamos da importância da sensação física transmitida pelos produtos, falamos dos estímulos sensoriais que estes nos causam quando em interação ao ambiente. Podemos assumir esta situação como uma oportunidade de aproximar o 
design do consumidor, no objetivo não apenas de cobrir e proteger o corpo de condições climáticas e ambientais, mas acima disso, de promover a sua funcionalidade como um objeto interativo, capaz de se tornar parte do próprio usuário, gerando valores que vão além do sua característica física e estética.

Os consumidores buscam isso, cada vez mais estarão carentes de sensações prazerosas e de interação positiva com seus produtos. E por isso, a ergonomia se mostra uma importante aliada na construção destes produtos, e em parceria com o design, agrega a metodologia adequada na criação de soluções emocionais para a captação da afetividade experiencial dos usuários.

\section{Artigo recebido em Julho de 2015. Aprovado em Setembro de 2015 \\ DOI:http://dx.doi.org/105965/1982615x08172016287}

\section{Referências bibliográficas}

CARVALHO, Lilian Vieira Rodrigues de. Design e Emoção: O papel do designer no consumo de produtos de moda. Universidade do Minho. Escola de Engenharia. Portugal, 2013.

CEPELASSI, Carla Hidalgo; VALARELli, Ivan de Domênico (Orientador). Metodologia Projetual para Produtos de Moda e a sua Interface com as Tabelas de Medidas do Vestuário. Dissertação de Mestrado. Universidade Estadual Paulista. Faculdade de Arquitetura, Artes e Comunicação. Bauru: 2010.

DAMÁSIO, António R. Em busca de Espinosa. São Paulo: Schwarcz, 2004.

GOMES FILHO, João. Gestalt do objeto: sistema de leitura visual da forma. São Paulo: Escrituras, 2009.

IIDA, Itiro. Ergonomia: projeto e produção. São Paulo: Blucher, 2005.

NORMAN, Donald A. Design emocional: por que adoramos (ou detestamos) os objetos do dia-a-dia. Rio de Janeiro: Rocco, 2008. 
ROSA, Lucas da; MORAES, Anamaria de (Orientadora). Vestuário Industrializado: Uso da Ergonomia nas Fases de Gerência de Produto. Criação, Modelagem e Prototipagem. Tese de Doutoramento. Universidade Católica do Rio de Janeiro: Rio de Janeiro, 2011.

SALVI, Naiane Cristina; SCHULTE, Neide. Equívocos da Sustentabilidade e o Caso de Marcas "EcoFictícias". E-periódico Moda Palavra, Ano 7, n.14, Jul-Dez 2014, Florianópolis: Universidade do Estado de Santa Catarina, 2014.

SILVEIRA, Icleia; SPITZ, Rejane, (Orientadora). Um modelo para capacitação dos instrumentos do sistema CAD para vestuário e dos modelistas com foco na gestão do conhecimento. Tese de Doutorado. PUCRIO: 2011. 